\title{
Taxon recruitment of the arctic flora: an analysis of phylogenies
}

\author{
Matthias H. Hoffmann and Martin Röser \\ Martin-Luther-University Halle-Wittenberg, Institute of Biology, Am Kirchtor 3, D-06108 Halle, Germany
}

Author for correspondence:

Matthias H. Hoffmann

Tel: +49 3455526229

Email: matthias.hoffmann@botanik.uni-

halle.de

Received: 30 October 2008

Accepted: 7 January 2009

New Phytologist (2009) 182: 774-780

doi: 10.1111/j.1469-8137.2009.02782.x

Key words: arctic flora, ecosystem evolution, meta-data analysis, parallel evolution, species diversity, species radiation.

\section{Summary}

- The Arctic is the endpoint of many climatic gradients and is presently occupied by c. 2200 vascular plant species. Glaciation started in the Middle Eocene but a significant expansion of the Greenland ice shield occurred only c. 3.2 million yr ago, leading to the expansion of the treeless circumpolar arctic tundra.

- Available molecular phylogenetic studies were evaluated for 148 of 374 genera occurring in the Arctic to determine the relative roles of their independent origins and their diversification in the development of the contemporary arctic flora.

- The number of arctic species paralleled the total number of species in a genus. Multiple arctic species within a genus originated mostly independently of each other and from different lineages. Minor radiations occurred in only a few genera and major radiations were absent.

- Mostly parallel evolution of arctic taxa from nonarctic ancestors, supposedly of different ages of origin, scarcity of radiations and rarity of endemics are main features of the arctic flora.

\section{Introduction}

Throughout much of the Tertiary, most of the Arctic, which is now cold and treeless, was covered with deciduous and coniferous forests (Murray, 1995; McIver \& Basinger, 1999). Global temperatures began to decrease in the Middle Eocene (c. 45 million yr ago (mya)) when temporary ice sheets formed (Moran et al., 2006). The more recent expansion of the Greenland ice shield c. 3.2 mya corresponds with the emergence of patches of the Arctic tundra ecosystem (Matthews, 1979; Matthews \& Ovenden, 1990), whose extensions varied largely during late Pliocene and Pleistocene (Svendsen et al., 2004). Rapid cooling during the late Tertiary created unprecedented open ecological space for organisms that were already adapted to low temperatures and short growing periods. Thus, the mountain florae of America and Eurasia have been considered major sources of arctic species (Hultén, 1958; Tolmachev, 1960; Hedberg, 1992; Abbott et al., 2000). This is supported, first, by the distribution of many species in both the Arctic and the high mountains of southern Eurasia and North America (Tolmachev, 1960; Tkach et al., 2008c) and, second, by many molecular phylogeographic studies, which have revealed Pleistocene survival in southern refugia and migration of populations to higher latitudes after the retreat of the ice sheets (Hewitt, 1996, 2000; Abbott et al., 2000; Abbott \& Brochmann, 2003).
During the glacial periods arctic plants may also have temporarily survived in the vicinity of glaciers to where they migrated with the expanding or retreating ice. Recent molecular phylogenetic studies have contributed substantially to elucidating the origin of such taxa. For example, if arctic taxa are nested within an entirely nonarctic lineage it is likely that they colonized the Arctic only secondarily and did not originate in this region (e.g. Elymus; Liu et al., 2006).

In situ origin of arctic plants in the tundra and a later colonization of high southern mountains or other habitats is the alternative hypothesis. In a phylogenetic framework such taxa would be nested within arctic clades as found in our study on arctic Artemisia for A. punctigera Krasch. ex Poljak. from dune habitats of Sakhalin (Tkach et al., 2008b). However, this species is very closely related to the arctic Artemisia arctica Less. and may be conspecific. Artemisia is one of the most speciesrich genera of the Arctic and its arctic species evolved from time to time in the phylogeny of the genus, independently within different lineages. There were no major radiations of the type starting with a single or few ancestors that invaded the Arctic and subsequently split into different species. Moreover, a clear principal source of origin of arctic taxa has not been discernable in this genus, since arctic species had southern sister taxa in quite different vegetation types. In addition the southern high mountains, steppes of the northern hemisphere have served as 
New

an important provenance for the recruitment of arctic taxa (Tkach et al., 2008b).

To determine whether the pattern seen in Artemisia is accidental or generally representative of the taxon recruitment of the contemporary arctic flora we explored a large number of phylogenetic studies conducted on seed plants, ferns and fern-allies occurring in this region. We also examined whether speciation by the radiation of single lineages (Baldwin \& Sanderson, 1998; Richardson et al., 2001; Linder \& Hardy, 2004; Barraclough, 2006) was common in the Arctic. Specifically, we posed the following questions: Is the number of arctic species in a genus correlated with the total number of species (in those genera that contain arctic species)? In other words, do large genera of the northern hemisphere possess more arctic species than smaller genera? Do the arctic species originate from a few evolutionary splits or do they occur repeatedly and in parallel in the phylogeny of the genera? Are the numbers of evolutionary transitions generating arctic species related to the number of arctic species?

\section{Materials and Methods}

According to most phytogeographical delineations (Takhtajan, 1986; Yurtsev, 1994; Elvebakk et al., 1999) the Arctic is considered to be the area north of the boreal tree line and comprises three subzones: the arctic desert normally found at highest latitudes, the moss and lichen tundra and the southern forest tundra with scattered occurrences of trees and shrub species, many of which also have large boreal ranges. Of the Eurasian arctic flora less than $5 \%$ of species are endemic to the Arctic (Tkach et al., 2008c). The present study deals with the entire arctic flora (in the following 'arctic plants' is defined as plants occurring in the Arctic). It thus includes not only the arctic endemics but all species present in the Arctic even if they have partial ranges or even their widest ranges outside the Arctic. Nevertheless, many of them are important constituents of the arctic flora dominating arctic landscapes and occur in all subzones (cf. examples studied by Alsos et al., 2007).

The arctic species inventory analysed in this study is compiled from the 'Arctic Flora of the former Soviet Union' (Tolmachev, 1960-1987) and the 'Panarctic Flora Project' (PAF; Nordal \& Razzhivin, 1999, online http://www.binran.ru/infsys/ paflist/taxon/taxonomy.htm). The genera Taraxacum and Hieracium were excluded from analysis because of the absence of a comprehensive systematic treatment of their species, which reproduce mainly by agamospermy as genetic clones.

We searched the ISI Web of Knowledge (http://www. isiwebofknowledge.com/) for molecular phylogenetic studies conducted to date on the vascular plants of the Arctic. Genera revealed the most suitable taxonomic entities for our investigation because this taxonomic unit was addressed in most molecular phylogenetic studies and frequently turned out to be monophyletic. If there was a completely resolved phylogeny of the vascular plants, major clades could be used instead of genera to infer their species' diversity and the number of splits leading
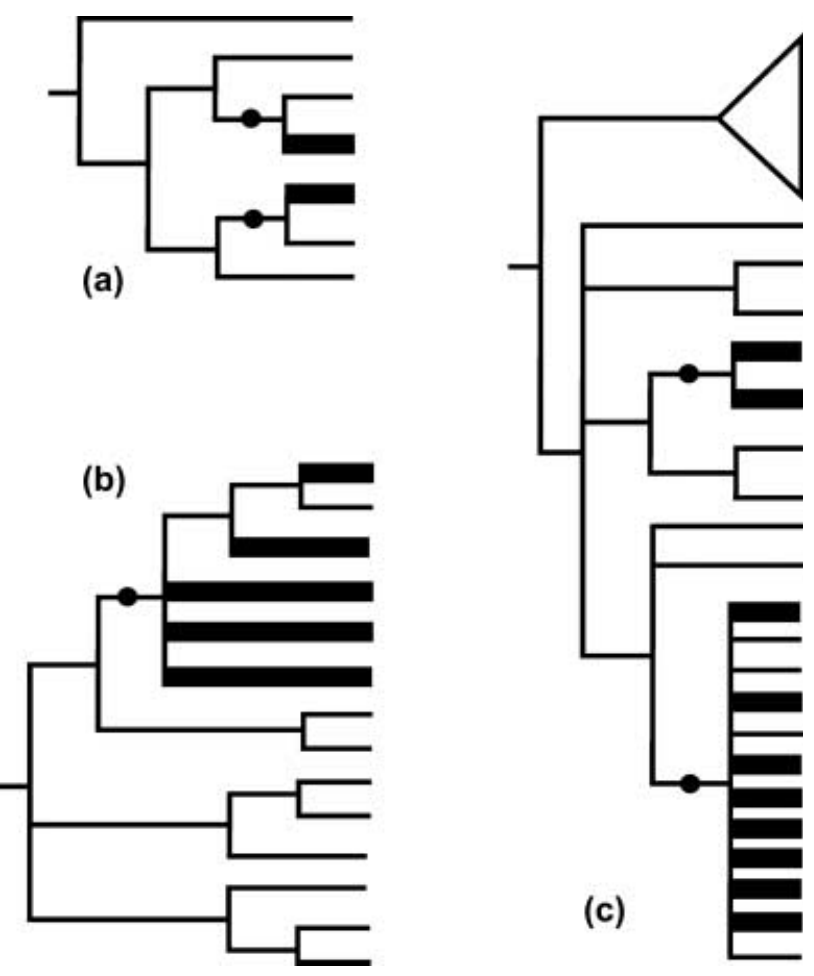

Fig. 1 Different types of evolutionary splits between nonarctic (thin branches) and arctic species or lineages (bold branches). Arctic branches separated from each other by branches of nonarctic taxa originated most likely independently (black dots). If there is a polytomy comprising arctic and nonarctic taxa (marked node in (b) and lower node in (c)), only one split is counted as the most parsimonious estimate. (b) and (c) also show likely radiations of arctic clades. The phylogenetic trees in (b) and (c) may have different interpretations taking the unresolved clades into account. The most parsimonious interpretation of (b) is one transition, resulting in five arctic taxa, but with one reversal. If the basal polytomy in (b) is a ladder, then there could be a maximum of five transitions to arctic taxa, with one species derived from each. If the basal three taxa form a clade, then there could be three transitions, one resulting in three arctic taxa and the other two in one arctic taxon each. The polytomy of (c), depending on how it is resolved, could have anywhere from one to eight transitions to arctic taxa with zero to four reversals. The triangle in (c) represents an entirely nonarctic clade. Simplified and redrawn from studies of (a) Albach et al. (2004), (b) Schneeweiss et al. (2004) and (c) Scheen et al. (2004).

to arctic taxa. For each of the 181 studies identified (see the Supporting Information, Table S1), we recorded the number of evolutionary splits between the species/lineages that were entirely nonarctic and those that were arctic or contained arctic taxa (see Fig. 1). In addition to recording the minimum number of splits as the most parsimonious interpretation of the trees, the possible maximum number of transitions to arctic species/ lineages were also counted. The latter takes into account uncertainties that arise from polytomies in the phylogenetic trees. Possible reversals (i.e. the evolution of nonarctic taxa from arctic progenitors) were also counted (Table S1) but we have 
an a priori belief that they are not very likely given the short time the clades have been able to colonize and to diversify in the Arctic. The depth of the phylogeny at which arctic sister lineages were identified varied among the studies and also depended on their taxon sampling. The different levels of the phylogeny, at which independent splits were defined, corresponded to different ages of arctic taxa (Tkach et al., 2008a) and thus should not affect the conclusions about the number of evolutionary splits leading to arctic species.

Reticulation via hybridization and allopolyploidy occurs in some genera of the Arctic (Brochmann \& Brysting, 2008; Jordon-Thaden \& Koch, 2008), whereas others show no signs of reticulation (e.g. Artemisia, Tkach et al., 2008b). Our study deals exclusively with the nodes in molecular phylogenetic studies that first gave rise to clades encompassing arctic species. If reticulation patterns had already played a role in the relatively basal nodes but had been overlooked by the original research, this error would inevitably have been carried over to our study. Allopolyploid speciation and occurrences of cryptic species (such as in Draba) may underestimate radiations in some genera but probably do not affect the general conclusions of taxon recruitment of the Arctic.

To reflect the different statistical support of tree topologies two categories were used (Figs 3, 4): first, nodes with > 85\% in maximum parsimony bootstrap and maximum likelihood or $>0.95$ in Bayesian posterior probability and, second, nodes with lower support or trees without support values. Numbers of arctic, nonarctic and entire species number per genus were taken from the original studies. If no total species number was recorded, we followed Mabberley (1997). The relationships between arctic and total species number, the number of evolutionary splits and the arctic species numbers of the genera were studied by correlation analyses using the software SPSS (SPSS Inc., 1999). Linear regression was applied to answer the question of whether large genera could produce more arctic species per split than smaller genera.

\section{Results}

A total of 2185 species and subspecies from 374 genera and 90 families present in the Arctic were counted. The total species number of a genus was a good predictor of the number of its arctic species (Pearson correlation coefficient $r=0.533, n=374$, $P<0.0001$; Fig. 2). Genera that are species-rich elsewhere in the northern hemisphere are also represented by more species in the Arctic. In some genera all species occupy at least parts of the Arctic (e.g. Andromeda, Beckmannia, Eriophorum and Hippuris), whereas other species-rich genera comprise only a relatively low number of species growing in arctic conditions (e.g. Astragalus, Carex, Senecio and Vaccinium).

The 181 molecular phylogenetic investigations evaluated in this study encompassed 148 of 374 arctic plant genera (c.40\%) and 649 arctic species (c. 30\%) from many different families (Table 1 1). Investigations ranged from species-poor genera (e.g.

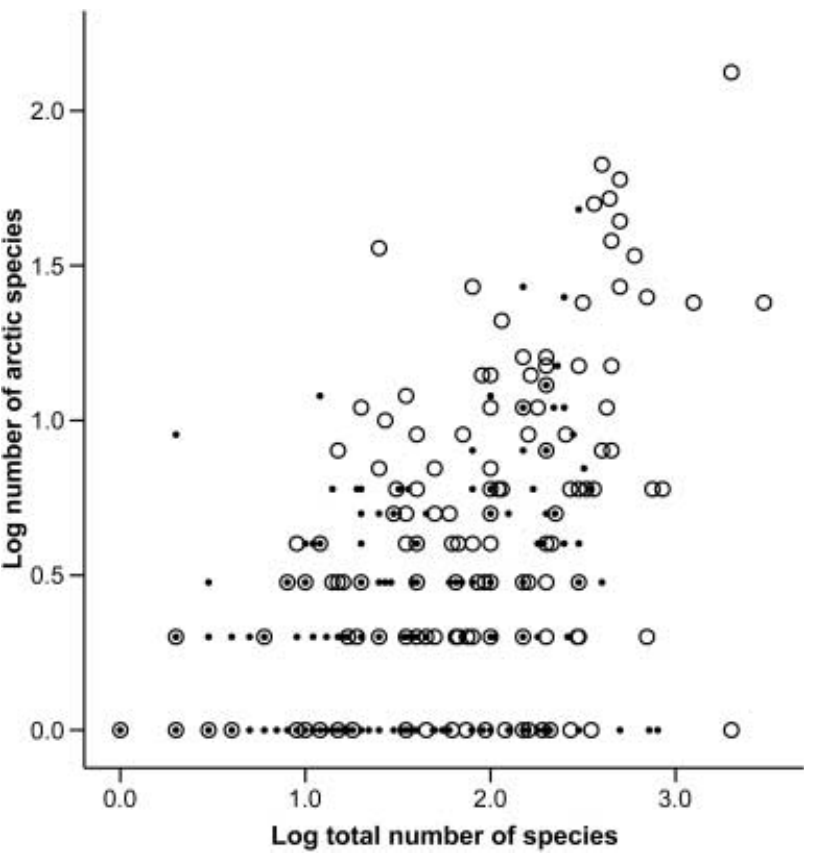

Fig. 2 Total numbers of species and numbers of arctic species in the 374 genera recorded for the Arctic (Pearson correlation coefficient $r=0.533, n=374, P<0.0001$ ). Circles denote genera with available species-level molecular phylogenetic studies (see the Supporting Information, Table S1) and dots denote genera not studied molecularly. The two points above the line of equality refer to Dryas and Puccinellia, in which the number of species within the Arctic (Nordal \& Razzhivin, 1999) exceeds the total number of species per genus recorded by Mabberley (1997).

Scheuchzeria) to species-rich genera. Carex, the largest genus in the Arctic, was investigated by no less than five studies. Arctic species were mostly better sampled than nonarctic species (Fig. S1).

The number of evolutionary splits in a genus leading to clades comprising arctic species strongly correlates with the number of arctic species per genus included in the molecular phylogenetic studies (Pearson correlation coefficient $r=0.603, n=181$, $P<0.001)$. The observed number of splits also correlates with the species richness of the genera (Pearson correlation coefficient $r=0.384, n=181, P<0.001)$. The number of arctic species per evolutionary split is on average less than two (Fig. 3). This evidence is slightly more pronounced considering the possible maximum number of transitions to arctic species/lineages (Fig. S2). This indicates that arctic species within a genus evolved mainly independently of each other and not by major rapid radiation. Only a few arctic species of some species-rich genera evolved from minor radiations (Draba, Saxifraga and Androsace subg. Douglasia in Fig. 1b, and Cerastium in Fig. 1c). With improved taxon sampling the position of some genera in Fig. 3 may change slightly, for example that of Carex because many of its arctic species have not been molecularly studied to date.

Plotting the relation between the observed numbers of splits and of arctic species on logarithmic axes recognizes the fact that species number increases exponentially assuming constant 
New

Fig. 3 Number of arctic species originated per evolutionary split (most parsimonious interpretation of the phylogenies) in comparison with the taxon sampling density of the molecular phylogenetic studies evaluated. The $x$-axis shows the ratio of arctic species included in the molecular study to the total number of arctic species per genus, thus indicating the completeness of arctic taxon sampling. The further right the study the more complete is the sampling. The $y$-axis shows the numbers of arctic species that originated after a split between nonarctic and arctic lineages. Studies with statistically supported nodes are denoted by circles, those without are denoted by triangles (see the Materials and Methods section). Symbol sizes indicate the number of arctic species per genus not sampled in the respective studies. The studies on Poa are biased because of their focus on arctic taxa (see the Supporting Information, Table S1). There is no significant correlation between taxon sampling density and the number of arctic taxa originating per split (Pearson correlation coefficient $=-0.065, n=181$, $P=0.391$ for the total data set).

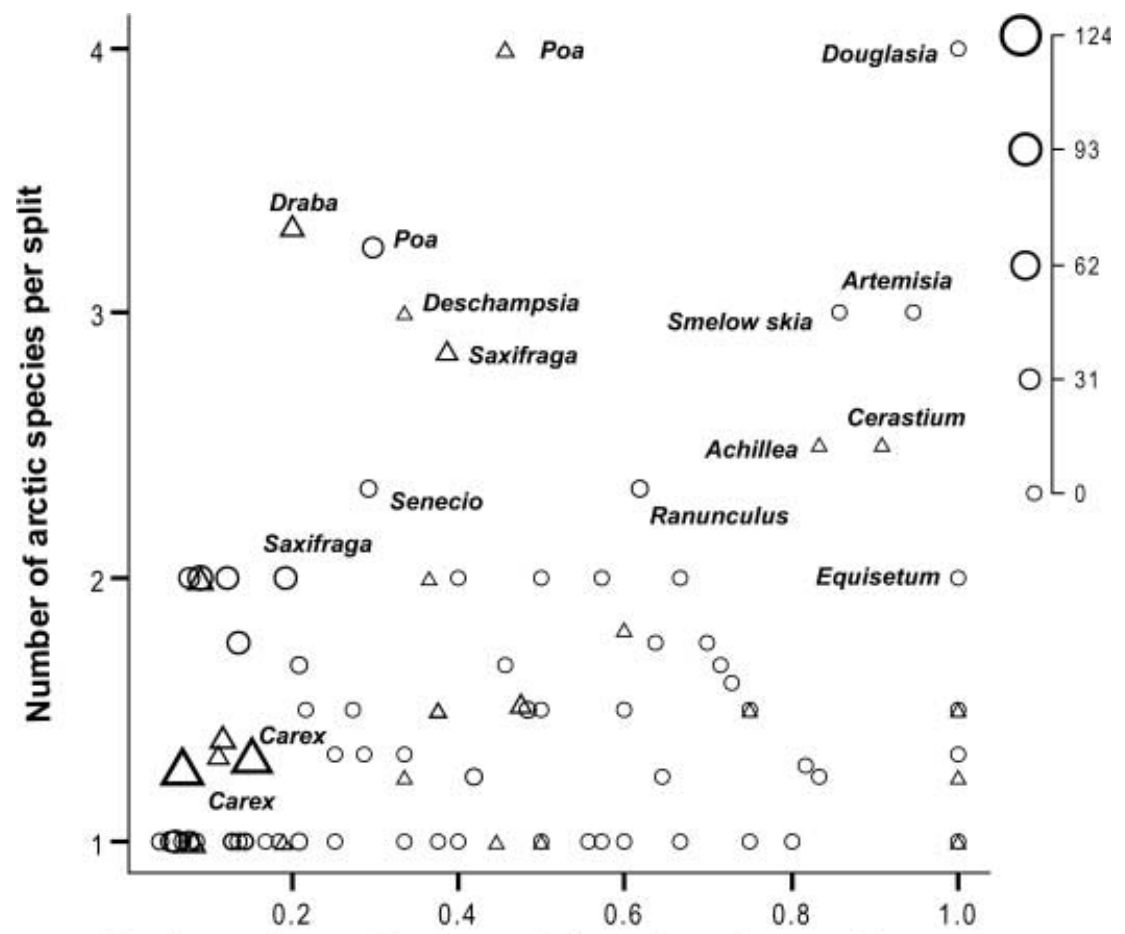

Ratio arctic species in study / total number arctic species diversification rates (Fig. 4). A linear regression reveals slopes greater than 1 (linear regression coefficient $=1.176, n=143$, $P<0.001$ for the highly supported set; linear regression coefficient $=1.399, n=181, P<0.001$ for the total data set). A regression slope of 1 would indicate that the average number of arctic species per split does not increase with more splits. Slopes greater than 1 indicate that the more splits occur - a feature connected with the sizes of the genera in terms of their species richness - the more arctic species evolve. Large genera thus tend to have, on average, more arctic species per evolutionary split leading to a clade with arctic taxa than smaller genera.

\section{Discussion}

The significant positive correlation between the total species number of a genus and the number of its arctic species suggests the overall capability of genera to diversify is an important precondition for the origin of arctic species. The repeated parallel origin of arctic taxa in the phylogeny of many genera indicates that the required changes in physiology or development to adapt to arctic environmental conditions can be accomplished comparatively easily in these genera. Although the number of observed evolutionary splits giving rise to arctic taxa depends in principle on the taxon sampling of the evaluated molecular phylogenetic studies, the absence of major radiations is well supported by the significant correlation between the number of evolutionary splits giving rise to arctic species and the number of arctic species.

The absence of species' radiation in the Arctic is surprising because several prerequisites are seemingly fulfilled: the avail- ability of new ecological spaces without competitors (Schwarzbach \& Kadereit, 1995; Schluter, 2000; Coyne \& Orr, 2004) and sufficient time since the emergence of the tundra environments. In most phylogenetic studies of the arctic flora either no molecular clock estimates were available or the clades with arctic taxa were not dated (Table S1). However, for three arctic species of Androsace (Primulaceae) Wang et al. (2004) obtained very different divergence times when compared with their nonarctic congeners (A. filiformis, c. $11 \mathrm{mya}$; A. septentrionalis, $c$. 5 mya; $A$. chamaejasme, $c$. 1 mya). By contrast, the small radiation in Douglasia (syn. Androsace subg. Douglasia) appears to be much younger (Schneeweiss et al., 2004). Depending on the method, the split between Androsace and Douglasia dates between 3.89 and 0.91 mya. The lower limit is close to the estimate for the first appearance of a continuous tundra biome (Matthews, 1979; Matthews \& Ovenden, 1990). However, taxa of Douglasia present in the Arctic belong to the rather terminal clades in that group and may be much younger. A node within the arctic clade was dated between 1.86 mya and 0.39 mya clearly younger than the origin of the arctic tundra. Our analysis of divergence times for arctic Artemisia also revealed a pattern of a temporal varying evolution of arctic species (Tkach et al., 2008a). One lineage of arctic Artemisia species predates the formation of the arctic biome (c. 7-17 mya, $A$. androsacel A. senjaviensis/A. glomerata clade), whereas several other lineages split from their nonarctic congeners after the origin of the tundra (i.e. they are younger than 3 mya). Other time estimates are available for the tree species Pinus sylvestris and Pinus pumila (Eckert \& Hall, 2006) that have wide boreal ranges that extend 


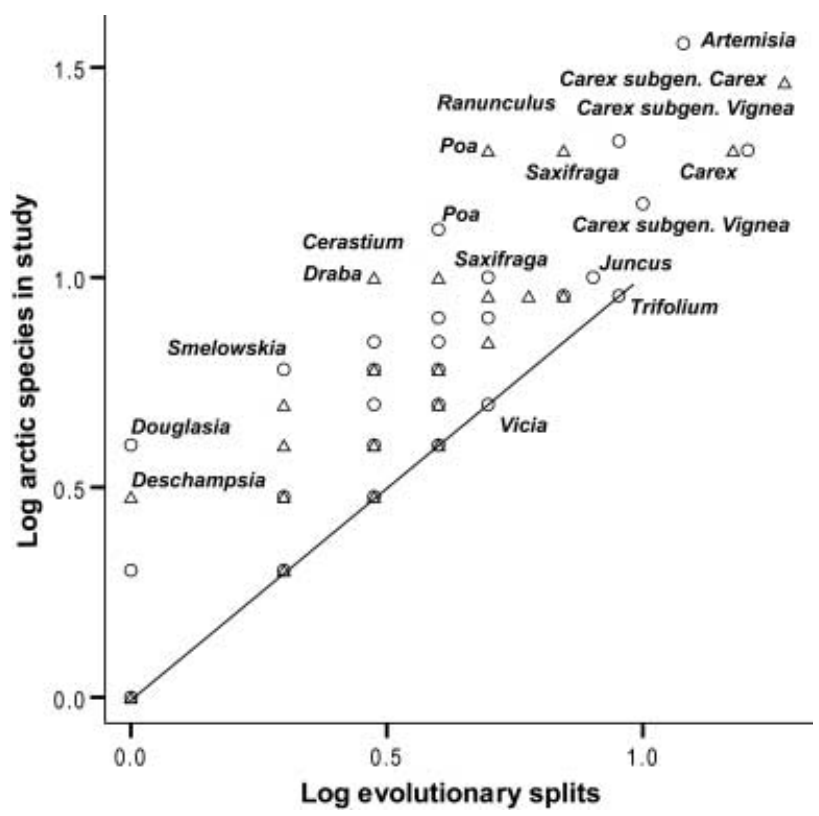

Fig. 4 Number of arctic species and evolutionary splits that gave rise to them. Circles denote splits statistically supported in the original molecular phylogenetic studies, triangles denote unsupported nodes (see the Materials and Methods section). The line is the $1: 1$ diagonal. Several points are shared by different genera (see the Supporting Information, Table S1). The supported data set (circles) has a linear regression coefficient $=1.176, n=143, P<0.001$ and the total set a linear regression coefficient $=1.399, n=181, P<0.001$.

into the low Arctic. Pinus pumila diverged c. 12 mya and P. sylvestris c. 5 mya from their nonarctic congeners. These few data suggest that species of the Arctic may have split at different times from their nonarctic sisters. Perhaps, some species of Artemisia, Androsace and Douglasia may have evolved in arctic ecosystems, whereas the splits in Pinus and parts of Artemisia and Androsace predate the formation of the first patches of arctic tundra c. 3.2 mya. Such a temporal varying taxon recruitment has also been reported for other ecosystems (Linder \& Hardy, 2004; Barraclough, 2006; Ricklefs et al., 2006). Further examples of ancient and recent speciation in the Arctic, particularly of polyploid origin, were observed in Saxifraga and Draba (for review see Abbott \& Brochmann, 2003). Ongoing diversification of arctic plants may also be inferred from the observation of cryptic species (Brochmann et al., 1993; Grundt et al., 2006) and high levels of genetic diversity among populations of arctic plants (Abbott et al., 2000; Hewitt, 2000). Perhaps, this might indicate a long waiting time to speciation or be a sign of radiation in its infancy.

The relative paucity of species in the Arctic can be attributed to several factors. The short vegetation period in the Arctic seems to act against some life forms. Plants with a rapid generation turnover (i.e. annuals and biennials with a limited life-span between germination, seed production and individual death) are virtually absent from the Arctic. Tree species are only scattered in the southern forest tundra. Most abundant life forms of the
Arctic comprise perennial herbs and low shrubs (species usually having long juvenile periods and a slow generation turnover; Eriksson \& Bremer, 1992; Dodd et al., 1999). This life-form may reduce the effective number of generations in many species of the Arctic and thus speciation.

Other potential reasons for the low species number of the Arctic were inferred from global assessments of biodiversity. Current models on worldwide species richness patterns revealed that, in addition to area size and habitat heterogeneity (Ricklefs, 2004; Sarr et al., 2005), relatively few environmental parameters are necessary to explain latitudinal gradients in diversity. Of these, thermal- and water-energy-coupled factors are of great significance (Woodward, 1987; Kreft \& Jetz, 2007). Kinetic effects of temperature are discussed for latitudinal clines of speciation and as potential reasons of the paucity of radiations in the North (Allen et al., 2006).

Assuming that earlier glacial-interglacial cycles had detrimental effects on the diversification of the arctic flora at the species level (Hewitt, 2000), the observed pattern of multiple parallel origins of arctic plants could alternatively be explained by the extinction of earlier radiations. If all but one or only a few species from earlier radiations became extinct, particularly if there was insufficient compensation by migration or dispersal, both evolutionary scenarios are hard to distinguish. Some degree of compensation by migration must be expected, since arctic plants show considerable rates of long-distance dispersal (Alsos et al., 2007). The putative extinction may have occurred not only during glacial periods when the arctic areas were largely covered by ice sheets, but also during interglacial periods at times of higher temperatures. During these interglacial periods temperature was sometimes higher than current temperatures (Francis et al., 2006), which certainly affected the space available for the arctic flora. The treeless arctic ecosystem most likely occupied a much smaller area than today.

Questions concerning how and when the arctic flora assembled and how it evolved need to be addressed in the future by in-depth molecular phylogenetic research to complement much better information available from the fields of population genetics and phylogeography (Brochmann et al., 1993; Abbott et al., 2000; Grundt et al., 2006). The first overview on the taxon recruitment of the arctic flora obtained in this study clearly indicates patterns of mostly parallel evolution of arctic taxa from nonarctic lineages, very different ages of their origin, a scarcity of evolutionary radiations and corroborates the rarity of endemics for the arctic flora.

\section{Acknowledgements}

We thank D. Ackerly, R. E. Ricklefs and anonymous reviewers for helpful comments on the manuscript.

\section{References}

Abbott RJ, Brochmann C. 2003. History and evolution of the arctic flora: in the footsteps of Eric Hultén. Molecular Ecology 12: 299-313. 
New

Abbott RJ, Smith LC, Milne RI, Crawford RMM, Wolff K, Balfour J. 2000. Molecular analysis of plant migration and refugia in the Arctic. Science 289: 1343-1346.

Albach DC, Martínez-Ortega MM, Fischer MA, Chase MW. 2004. Evolution of the Veroniceae: a phylogenetic perspective. Annals of the Missouri Botanical Garden 91: 275-302.

Allen AP, Gillooly JF, Savage VM, Brown JH. 2006. Kinetic effects of temperature on rates of genetic divergence and speciation. Proceedings of the National Academy of Sciences, USA 103: 9130-9135.

Alsos IG, Eidesen PB, Ehrich D, Skrede I, Westergaard K, Jacobsen GH, Landvik JY, Taberlet JY, Brochmann C. 2007. Frequent long-distance plant colonization in the changing Arctic. Science 316: 1606-1609.

Baldwin BG, Sanderson MJ. 1998. Age and rate of diversification of the Hawaiian silversword alliance (Compositae). Proceedings of the National Academy of Sciences, USA 95: 9402-9406.

Barraclough TG. 2006. What can phylogenetics tell us about speciation in the Cape flora? Diversity and Distributions 12: 21-26.

Brochmann C, Borgen L, Stedje B. 1993. Crossing relationships and chromosome numbers of Nordic populations of Draba (Brassicaceae), with emphasis on the D. alpina complex. Nordic Journal of Botany 13: 121-147.

Brochmann C, Brysting AK. 2008. The Arctic - an evolutionary freezer? Plant Ecology and Diversity 1: 181-195.

Coyne JA, Orr HA. 2004. Speciation. Sunderland, MA USA: Sinauer.

Dodd ME, Silvertown J, Chase MW. 1999. Phylogenetic analysis of trait evolution and species diversity variation among angiosperm families. Evolution 53: 732-744.

Eckert AJ, Hall BD. 2006. Phylogeny, historical biogeography, and patterns of diversification for Pinus (Pinaceae): phylogenetic tests of fossil-based hypotheses. Molecular Phylogenetics and Evolution 40: 166-182.

Elvebakk A, Elven R, Razzhivin VYU. 1999. Delimitation, zonal and sectorial subdivision of the Arctic for the Panarctic Flora Project. Skrifter Det Norske Videnskaps-Akademi i Oslo. I. Matematisk-Naturvidenskapelig Klasse, Ny serie 38: 375-386.

Eriksson O, Bremer B. 1992. Pollination systems, dispersal modes, life forms, and diversification rates in angiosperm families. Evolution 46: 258-266.

Francis DR, Wolfe AP, Walker IR, Miller GH. 2006. Interglacial and Holocene temperature reconstructions based on midge remains in sediments of two lakes from Baffin Island, Nunavut, Arctic Canada. Paleogeography, Paleoclimatology, Paleoecology 236: 107-124.

Grundt HH, Kjolner S, Borgen L, Rieseberg LH, Brochmann C. 2006. High biological species diversity in the arctic flora. Proceedings of the National Academy of Sciences, USA 103: 972-975.

Hedberg KO. 1992. Taxonomic differentiation in Saxifraga hirculus L. (Saxifragaceae) - a circumpolar arctic-boreal species of Central Asian origin. Botanical Journal of the Linnean Society 109: 377-393.

Hewitt G. 2000. The genetic legacy of the Quaternary ice ages. Nature 405: 907-913.

Hewitt GM. 1996. Some genetic consequences of ice ages, and their role in divergence and speciation. Biological Journal of the Linnean Society 58: 247-276.

Hultén E. 1958. The amphi-atlantic plants and their phytogeographical connections. Kungliga Svenska Vetenskapsakademiens Handlingar, Fjärde Serien 7: 1-340.

Jordon-Thaden I, Koch M. 2008. Species richness and polyploid patterns in Draba (Brassicaceae): a first global perspective. Plant Ecology and Diversity 1: 255-263.

Kreft H, Jetz W. 2007. Global patterns and determinants of vascular plant diversity. Proceedings of the National Academy of Sciences, USA 104: 5925-5930.

Linder HP, Hardy CR. 2004. Evolution of the species-rich Cape flora. Philosophical Transactions of the Royal Society of London - B 359: 1623-1632.
Liu Q, Ge S, Tang H, Zhang X, Zhu G, Lu BR. 2006. Phylogenetic relationships in Elymus (Poaceae: Triticeae) based on nuclear ribosomal transcribed spacer and chloroplast trnL-F sequences. New Phytologist 170: $411-420$.

Mabberley DJ. 1997. The plant book. Cambridge, UK: Cambridge University Press.

Matthews JR, Ovenden LE. 1990. Late Tertiary plant macrofossils from localities in Arctic/Subarctic North America: a review of the data. Arctic 43: 384-392.

Matthews JV. 1979. Tertiary and Quaternary environments: In: Danks HV, ed. Historical background for an analysis of the Canadian insect fauna. Canada and its Insect Fauna. Ottawa, Canada: Entomological Society of Canada, 31-86.

McIver EE, Basinger JF. 1999. Early Tertiary floral evolution in the Canadian high Arctic. Annals of the Missouri Botanical Gardens 86: 523-545.

Moran K, Backman J, Brinkhuis H, Clemens SC, Cronin T, Dickens GR, Eynaud F, Gattacceca J, Jakobsson M, Jordan RW et al. 2006. The Cenozoic palaeoenvironment of the Arctic Ocean. Nature 441: 601-605.

Murray DF. 1995. Causes of arctic plant diversity: origin and evolution. In: Chapin SS, Körner C, eds. Arctic and alpine biodiversity: patterns, causes, and ecosystem consequences. (Ecological Studies vol. 113). Berlin: Springer Verlag, 21-32.

Nordal I, Razzhivin VYU. 1999. The species concept in the High North. A Panarctic Flora initiative. Skrifter Det Norske Videnskaps-Akademi i Oslo. I. Matematisk-Naturvidenskapelig Klasse, Ny serie 38: 1-418.

Richardson JE, Weitz FM, Fay MF, Cronk QCB, Linder HP, Reeves G, Chase MW. 2001. Rapid and recent origin of species richness in the Cape flora of South Africa. Nature 412: 181-183.

Ricklefs RE. 2004. A comprehensive framework for global patterns in biodiversity. Ecology Letters 7: 1-15.

Ricklefs RE, Schwarzbach AE, Renner SS. 2006. Rate of lineage origin explains the diversity anomaly in the World's Mangrove vegetation. American Naturalist 168: 805-810.

Sarr DA, Hibbs DE, Huston MA. 2005. A hierarchical perspective of plant diversity. Quarterly Review of Biology 80: 187-212.

Scheen AC, Brochmann C, Brysting AK, Elven R, Morris A, Soltis DE, Soltis PS, Albert VA. 2004. Northern hemisphere biogeography of Cerastium (Caryophyllaceae): insights from phylogenetic analysis of noncoding plastid nucleotide sequences. American Journal of Botany 91: 943-952.

Schluter D. 2000. The ecology of adaptive radiation. Oxford, UK: Oxford University Press.

Schneeweiss GM, Schönswetter P, Kelso S, Niklfeld H. 2004. Complex biogeographic patterns in Androsace (Primulaceae) and related genera: evidence from phylogenetic analyses of nuclear internal transcribed spacer and plastid trnL-F sequences. Systematic Biology 53: 856-876.

Schwarzbach AE, Kadereit JW. 1995. Rapid radiation of North American desert genera of the Papaveraceae: Evidence from restriction site mapping of PCR-amplified chloroplast DNA fragments. Plant Systematics and Evolution (Supplement) 9: 159-170.

SPSS Inc. 1999. SPSS for Windows. Chicago, IL, USA: SPSS Inc.

Svendsen JI, Alexanderson H, Astakhov VI, Demidov I, Dowdeswell JA, Funder S, Gataullin V, Henriksen M, Hjort C, Houmark-Nielsen M et al. 2004. Late Quaternary ice sheet history of northern Eurasia. Quaternary Science Reviews 23: 1229-1271.

Takhtajan AL. 1986. The floristic regions of the world. Berkeley, CA, USA: University of California Press.

Tkach NV, Hoffmann MH, Röser M, von Hagen KB. 2008a. Temporal patterns of evolution in the Arctic explored in Artemisia L. (Asteraceae) lineages of different age. Plant Ecology and Diversity 1: 161-169. 
Tkach NV, Hoffmann MH, Röser M, Korobkov AA, von Hagen KB. 2008b. Parallel evolutionary patterns in multiple lineages of arctic Artemisia L. (Asteraceae). Evolution 62: 184-198.

Tkach NV, Röser M, Hoffmann MH. 2008c. Range size variation and diversity distribution in the vascular plant flora of the Eurasian Arctic. Organisms Diversity and Evolution 8: 251-266.

Tolmachev AI. 1960. Der autochthone Grundstock der arktischen Flora und ihre Beziehungen zu den Hochgebirgsfloren Nord- und Zentralasiens. Botanisk Tidsskrift 55: 269-276.

Tolmachev AI. 1960-1987. Arkticheskaya Flora SSSR. Vol. 1, 1960, Vol. 4, 1964, Moscow, Leningrad: Izdatelstvo Akademii Nauk. Vol. 2, 1964, Vol. 3, 1966, Vol. 5, 1966, Moscow, Leningrad: Nauka. Vol. 6, 1971, Vol. 7, 1975, Vol. 8-1, 1980, Vol. 8-2, 1983, Vol. 9-1, 1984, Vol. 9-2, 1986, Vol. 10, 1987. Leningrad: Nauka.

Wang YJ, Li XJ, Hao G, Liu JQ. 2004. Molecular phylogeny and biogeography of Androsace (Primulaceae) and the convergent evolution of cushion morphology. Acta Phytotaxonomica Sinica 42: 481-499.

Woodward FI. 1987. Climate and plant distribution. Cambridge, UK: Cambridge University Press.

Yurtsev BA. 1994. Floristic division of the Arctic. Journal of Vegetation Science 5: 765-776.

\section{Supporting information}

Additional supporting information may be found in the online version of this article.

Fig. S1 Linear regression of the percentages of arctic and nonarctic species treated in the 181 molecular phylogenetic studies evaluated.

Fig. S2 Number of arctic species originated per evolutionary split (maximum number of transitions to arctic species/ lineages) in comparison with the taxon sampling density of the molecular phylogenetic studies evaluated.

Table S1 List of molecular phylogenetic studies, from which information on the evolution of the arctic flora were obtained.

Please note: Wiley-Blackwell are not responsible for the content or functionality of any supporting information supplied by the authors. Any queries (other than missing material) should be directed to the New Phytologist Central Office.

\section{Pabout New Phytologist}

- New Phytologist is owned by a non-profit-making charitable trust dedicated to the promotion of plant science, facilitating projects from symposia to open access for our Tansley reviews. Complete information is available at www.newphytologist.org.

- Regular papers, Letters, Research reviews, Rapid reports and both Modelling/Theory and Methods papers are encouraged. We are committed to rapid processing, from online submission through to publication 'as-ready' via Early View - our average submission to decision time is just 29 days. Online-only colour is free, and essential print colour costs will be met if necessary. We also provide 25 offprints as well as a PDF for each article.

- For online summaries and ToC alerts, go to the website and click on 'Journal online'. You can take out a personal subscription to the journal for a fraction of the institutional price. Rates start at $£ 139$ in Europe/\$259 in the USA \& Canada for the online edition (click on 'Subscribe' at the website).

- If you have any questions, do get in touch with Central Office (newphytol@lancaster.ac.uk; tel +44 1524 594691) or, for a local contact in North America, the US Office (newphytol@ornl.gov; tel +1 865576 5261). 